\title{
Design, development and characterization of carrier mediated drug delivery system for effective management of Osteoarticular Tuberculosis
}

\section{Pratiksha Prabhu}

Dr Bhanuben Nanavati College of Pharmacy Department of Pharmaceutics

Trinette Fernandes

Dr Bhanuben Nanavati College of Pharmacy Department of Pharmaceutics

Pramila Chaubey

Shaqra University

Sujata Pralhad Sawarkar ( $\sim$ sujata.sawarkar@bncp.ac.in )

Dr Bhanuben Nanavati College of Pharmacy Department of Pharmaceutics https://orcid.org/00000003-0473-4979

\section{Research Article}

Keywords: Osteoarticular tuberculosis, Chitosan, mannose, ligand, conjugation

Posted Date: April 7th, 2021

DOl: https://doi.org/10.21203/rs.3.rs-383712/v1

License: (9) This work is licensed under a Creative Commons Attribution 4.0 International License. Read Full License 
Design, development and characterization of carrier mediated drug delivery system for effective management of Osteoarticular Tuberculosis

Pratiksha Prabhu ${ }^{1}$, Trinette Fernandes ${ }^{1}$, Pramila Chaubey²,Sujata P. Sawarkar*1

1. Department of Pharmaceutics, SVKM's Dr. Bhanuben Nanavati College of Pharmacy, University of Mumbai, INDIA.

2. Department of Pharmaceutics, College of Pharmacy, Shaqra University, Al-Dawadmi, Saudi Arabia.

\section{*Corresponding Author:}

Dr. Sujata P. Sawarkar

Professor in Pharmaceutics,

Department of Pharmaceutics,

SVKM's Dr. Bhanuben Nanavati College of Pharmacy,

Vile Parle, Mumbai, India.

Tel. 022-42332052

E-mail: sujata.sawarkar@bncp.ac.in, sujatasawarkar19@gmail.com

ORCiD: https://orcid.org/0000-0003-0473-4979 


\section{ABSTRACT:}

Tuberculosis (TB) is a potentially fatal contagious disease and is a second leading infectious cause of death in world. Bone and joint TB (BJTB)/ Osteoarticular TB is a secondary form of TB occurring most commonly due to hematogenous seeding of mycobacterium (MTB) from the primary site of infection. The prevalence of the disease is around 30 million globally and approximately $30 \%$ or 10 million cases exist in India. Osteoarticular tuberculosis, is found in about 10-20\% of all diagnosed tuberculosis, is the most common extrapulmonary tuberculosis. Osteoarticular TB is treated using standard regimen of $1^{\text {st }}$ and $2^{\text {nd }}$ line Anti- Tubercular drugs (ATDs) for extensive period of 8 - 20 months. These drugs are commonly administered in high doses by oral route or by intravenous route, because of their compromised bioavailability. The common drawbacks associated with conventional therapy are poor patient compliance due to long treatment period, frequent and high dosing and toxicity. Additionally failure by the patients to follow therapeutic regimen properly has given rise to development of resistance against these ATDs. This aspect marks for the need of formulations to eliminate these drawbacks. MTB is an intracellular pathogen of mononuclear phagocyte. This attribute makes nanotherapeutics an ideal approach for MTB treatment as macrophages capture nano forms. Polymeric nanoparticles are removed from the body by opsonization and phagocytosis, this forms an ideal strategy to target macrophage containing mycobacteria. To further improve targetability, the nanoparticles are conjugated with ligand, which serves as an easy substrate for the receptors present on the macrophage surface. The purpose of present work was to develop intra articular injectable insitu gelling system containing polymeric nanoparticles, which would have promising advantages over conventional method of treatment. The rationale behind formulating nanoparticle incorporated in situ gel based system was to ensure localization of the formulation in intra articular cavity along with sustained release and conjugation of nanoparticles with mannose as ligand to improve uptake by 
macrophages. Rifampicin standard ATD was formulated into Chitosan nanoparticles. Chitosan with $85 \%$ degree of deacetylation (DDA) and Sodium tripolyphosphate (TPP) as the crosslinking agent was used for preparing nanoparticles. The percent entrapment was found to be about $71 \%$. The prepared nanoparticles were conjugated with mannose. Conjugation of ligand was ascertained by performing Fourier transformed Infrared spectroscopy. The particle size was found to be in the range of $130-140$ $\mathrm{nm}$ and zeta potential of $38.5 \mathrm{mV}$. Additionally we performed scanning electron microscopy to characterize the surface morphology of ligand-conjugated nanoparticles. The conjugated Chitosan nanoparticles were incorporated into in situ gelling system comprising of Poloxamer 407 and HPMC K4M. The gelling system was evaluated for viscosity, gelling characteristics and syringeability. The drug release from conjugated nanoparticles incorporated in in situ gel was found to be about $70.3 \%$ at the end of 40 hours in simulated synovial fluid following zero order release kinetics. Based on the initial encouraging results obtained, the nanoparticles are being envisaged for ex-vivo cellular uptake study using TB infected macrophages

Keywords: Osteoarticular tuberculosis, Chitosan, mannose, ligand, conjugation 


\section{Graphical abstract:}

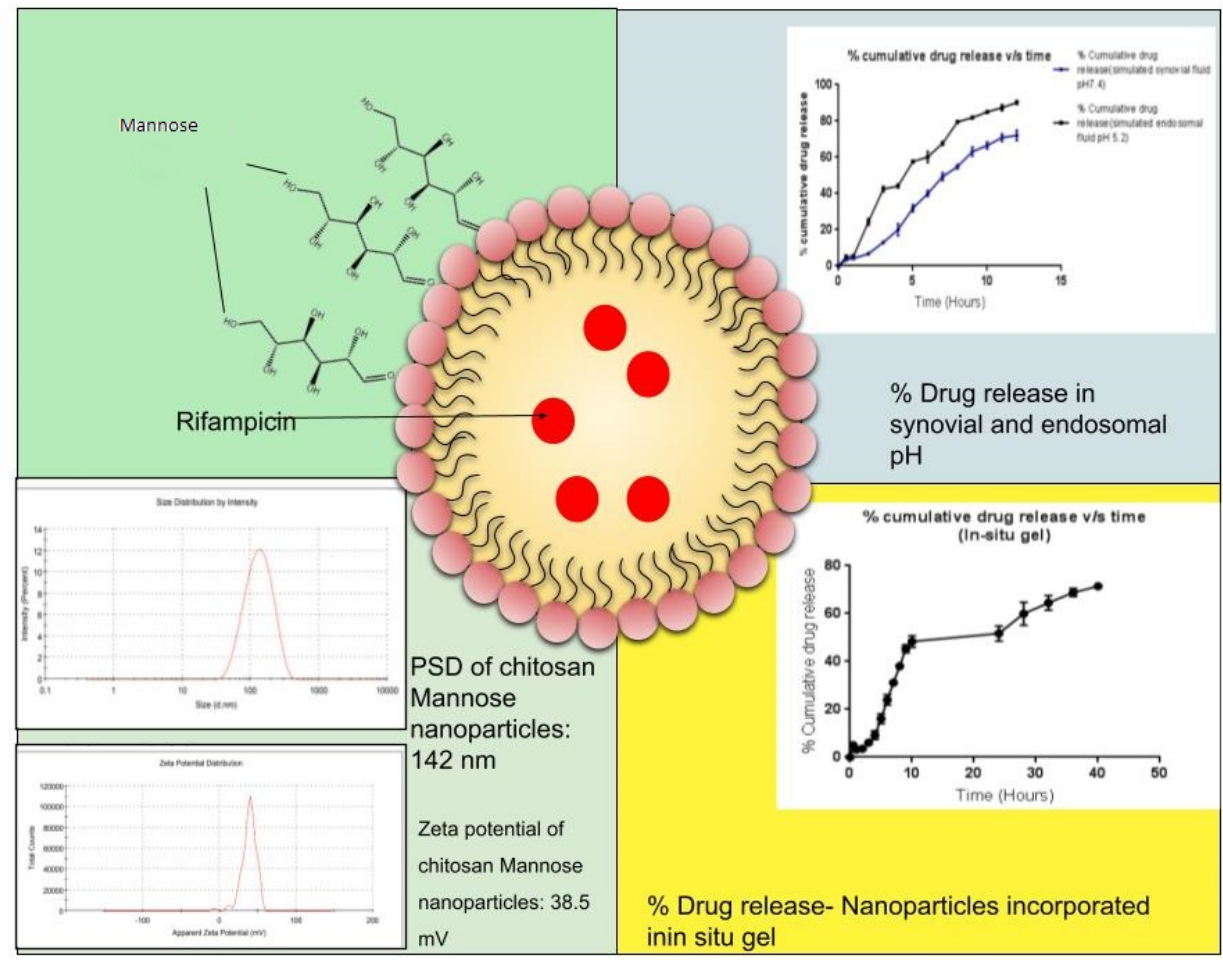

\section{List of abbreviations:}

TB: Tuberculosis

BJTB: Bone and joint Tuberculosis

MTB: Mycobacterium

ATDs: Anti- Tubercular drugs

TPP: Sodium tripolyphosphate

STAB: Sodium triacetoxy borohydride

HPMC: Hydroxy propyl methyl cellulose

DDA: Degree of deactylation

$\%$ EE: Percent entrapment efficiency

FTIR: Fourier Transformed Infrared Spectroscopy 
DSC: Differential Scanning Calorimetry

MCNPs: Mannose conjugated Chitosan Nanoparticles

PDI: Polydispersity index

\section{Word count: 4766 words}

\section{Number of figures: 7}

\section{Number of Tables: 10}

\section{Introduction:}

Tuberculosis (TB) is a potentially fatal contagious disease and is a second leading infectious cause of death in world. Bone and joint TB (BJTB)/ Osteoarticular TB is a secondary form of TB occurring most commonly due to hematogenous seeding of mycobacterium (MTB) from the primary site of infection(1). The prevalence of the disease is around 30 million globally and approximately $30 \%$ or 10 million cases exist in India. Osteoarticular tuberculosis, is found in about $10-20 \%$ of all diagnosed tuberculosis, is the most common extrapulmonary tuberculosis. Osteoarticular disease is seen after the principal lesions of lungs spreads phenomenally via lymphnodes (2). Osteoarticular TB is treated using standard regimen of $1^{\text {st }}$ and $2^{\text {nd }}$ line Anti- Tubercular drugs (ATDs) for extensive period of 8 20 months. The predisposing factors affecting success of therapy include patient compliance, therapy regimen, malnutrition, pre-existing diseases (3)(4). Osteoarticular TB behaves differently from pulmonary TB. The treatment is comparatively complex than pulmonary TB and requires combination therapy for longer duration around a year or two as destroying dormant population is quite challenging. Inadequate killing of MTB can cause relapse with variation in treatment response $(5,6)$ 
The conventional therapy regimens have been successful to some extent in bringing about, if not complete but at least partial eradication of TB. The drawbacks associated with currently available treatment mainly include long period of treatment, toxicity, increased frequency of dosing (7). All these factors lead to discontinuation of the therapy even before the completion of treatment. The repercussions of discontinued therapy are increased probability of MTB bacteria developing resistance to drug leading to ineffectiveness of treatment (8). Most of the drugs used for the treatment of TB belong to BCS II or IV. It is because of their compromised solubility or permeability resulting into poor bioavailability. As a result they are required to be administered in high doses by the oral route or by intramuscular/intravenous route (9). This marks for the need of evolving and developing modified formulations to eliminate these drawbacks. Nanocarriers have the potential to address some of the challenges like an ideal approach for MTB treatment as macrophages capture nanoforms with or without surface modifications (10). Various nanocarrier systems that have been extensively studied are polymeric and lipid nanoparticles, polymeric micelle, carbon nanotubes (11). The peculiar characteristic of nanocarriers is that they are removed from the body by opsonization and phagocytosis. This attribute forms an effective strategy to target macrophage containing mycobacteria. Although nano formulations can play an important role in effective treatment of $\mathrm{TB}$, their role in enhancing targetability is sometimes limited. In order to improve the targetability of nanoformulations, various ligands specific to the mycobacteria cell components or macrophage receptor are being envisaged(12) .Ligand anchored therapy is a strong and effective approach to execute drug delivery into selective target cells.. Studies have shown that apart from targeting, ligands provide shielding effect to drug carrier and prolong its circulation time in the bloodstream (13). In the present work we have formulated Chitosan nanoparticles loaded with first line therapy drug Rifampicin. The polymeric nanoparticles were conjugated with mannose as targeting ligand. The 
conjugated drug loaded polymeric nanoparticles were incorporated into intra articular injectable insitu gelling system. The rationale behind developing this formulation strategy was to ensure localization of the formulation in intra articular cavity along with sustained release and conjugation of nanoparticles with mannose as ligand to improve uptake by macrophages. It has been observed that mannose receptors are over expressed during mycobacterial infection. Hence mannosylated nanoparticle can serve as effective cargo to deliver the drug in to macrophageal cells hosting the mycobacteria (14)

\section{Materials and Method}

The active pharmaceutical ingredient, Rifampicin, was obtained as a gift sample from Lupin Pharmaceuticals Ltd., India. The natural polymer, Chitosan with $85 \%$ degree of acetylation from MatsyaFed, India, and other excipients such as Hydroxy propyl methyl cellulose K4M from Colorcon India Pvt. Ltd.), Poloxamer 407 (Sigma Aldrich), Mannose (Lobachemie Ltd.) Sodium Tripolyphosphate (TPP) (Lobachemie Ltd.), Sodium Triacetoxy Borohydride(STAB) (Lobachemie Ltd.) were obtained as gift sample. The other chemicals and solvents required for experimentation were procured from SD Fine Chemicals Ltd.

\subsection{Preparation of Rifampicin loaded Mannose conjugated Chitosan nanoparticles}

In order to formulate Rifampicin loaded mannose conjugated chitosan nanoparticles, mannose conjugated Chitosan polymer was prepared. Mannose conjugation was obtained by performing reductive deamination of Chitosan with D-Mannose (15). Chitosan was dissolved in Lactic acid solution $(1 \% \mathrm{w} / \mathrm{v})$ using overhead stirrer. This was followed by addition of aqueous solution of STAB and D-Mannose to the chitosan solution. The polymer was allowed to react with STAB and DMannose for a period of 2 days. On completion of reaction, unreacted mannose and STAB were removed. The prepared polymer was dried using Spray Drier (Labultima LU 222) maintaining inlet 
temperature at $50^{\circ} \mathrm{C}(16)$. The process was optimized for parameters like $\%$ STAB concentration and $\%$ D-Mannose concentration. The formation of conjugated polymer was ascertained by Fourier Transformed Infrared Spectroscopy (Figure 2D). Rifampicin, the model drug used for loading nanoparticles was subjected to preformulation studies wherein the purity of drug was assessed by performing Differential Scanning Calorimetry (DSC) and FTIR(Shimadzu IRAffinity-IS) (Figure 1 and 2A). Chitosan nanoparticles were produced by ionic gelation method using TPP as crosslinking agent

(17). In order to prepare nanoparticles, the conjugated polymer was dissolved in $2 \% \mathrm{w} / \mathrm{v}$ Lactic acid solution under magnetic stirring for 2 hours (18). On complete dissolution of polymer, the $\mathrm{pH}$ of the solution was adjusted to 5 using $1 \mathrm{M}$ Sodium Hydroxide. Rifampicin was first dissolved in Dimethylsulfoxide and Tween 80 mixture and then added to TPP solution. The process was optimized for parameters like DDA of Chitosan polymer concentration, TPP concentration, and drug and Tween 80 concentration, stirring speed. For the sake of comparative evaluation Rifampicin was encapsulated in non-conjugated Chitosan nanoparticles

\subsection{Evaluation of Rifampicin Loaded Mannose conjugated Chitosan Nanoparticles}

Rifampicin loaded Mannose conjugated Chitosan Nanoparticles (MCNPs) were evaluated for physicochemical characteristics like entrapment efficiency, particle size distribution and measurement of polydispersity index using Laser Diffraction measurement (Malvern Zetasizer Nano ZS), Zeta Potential (mV), Surface morphology by Scanning Electron microscopy (Zeiss Evo 50) (19). Drug release studies were performed by diffusion in simulated synovial fluid (pH 7.4) (20) and simulated endosomal fluid ( $\mathrm{pH}$ 5.2) (21) using dialysis membrane (Himedia 150). The drug release kinetics was predicted by computing regression coefficient of zero order, first order, Higuchi and Korsmeyer Peppas models (22) 


\subsection{Development and evaluation of In situ gelling system containing Mannose conjugated}

\section{Chitosan nanoparticles}

Various gelling agents such as Chitosan, Deacetylated Gellan Gum, Sodium Alginate, Poloxamer 407 in combination with HPMC K4M were used to formulate in situ gelling system (23). The composition and proportion of the polymers were optimized based on clarity, syringeability, gelation time, gelling capacity. Rifampicin loaded mannose conjugated chitosan nanoparticles were incorporated in in situ gelling system and evaluated for drug release for period of 40 hours (24)

\section{Results and Discussion:}

\subsection{Preparation of Rifampicin loaded Mannose conjugated Chitosan nanoparticles}

Rifampicin is a bactericidal drug which interferes with the synthesis of nucleic acids by inhibiting DNA-dependent RNA-polymerase. Rifampicin binds to the pocket of RNA polymerase beta subunit within the DNA/RNA channel but away from the active site. The drug is active against Gram-positive bacteria, mycobacterium species and some Gram-negative bacteria (25). The drug shows good $\mathrm{pH}$ dependent solubility at lysosomal $\mathrm{pH}$ of the macrophage. By conventional route Rifampicin is required to be administered in high and frequent doses in order to exhibit therapeutic effect. In order to counter and nullify some of these drawbacks we have formulated intraarticular injectable in-situ gelling system containing polymeric nanoparticles. The objective behind formulating nanoparticle incorporated in situ gel based system is to ensure localization of the formulation in intra articular cavity along with sustained release and easy access of nanoparticles to bone and joints thus, minimizing bio distribution to other parts. The drug was evaluated for preformulation testing to ascertain its purity and compliance with compendial standards. An endothermic peak assignable to melting point of Rifampicin was 
observed at $183-185^{\circ} \mathrm{C}$ indicating purity of active pharmaceutical ingredient (Figure 1). FTIR peaks were observed at wave numbers peculiar to the functional groups present in molecular structure of Rifampicin further confirmed the suitability and quality of the active pharmaceutical ingredient (Table 1 and Figure 2A).

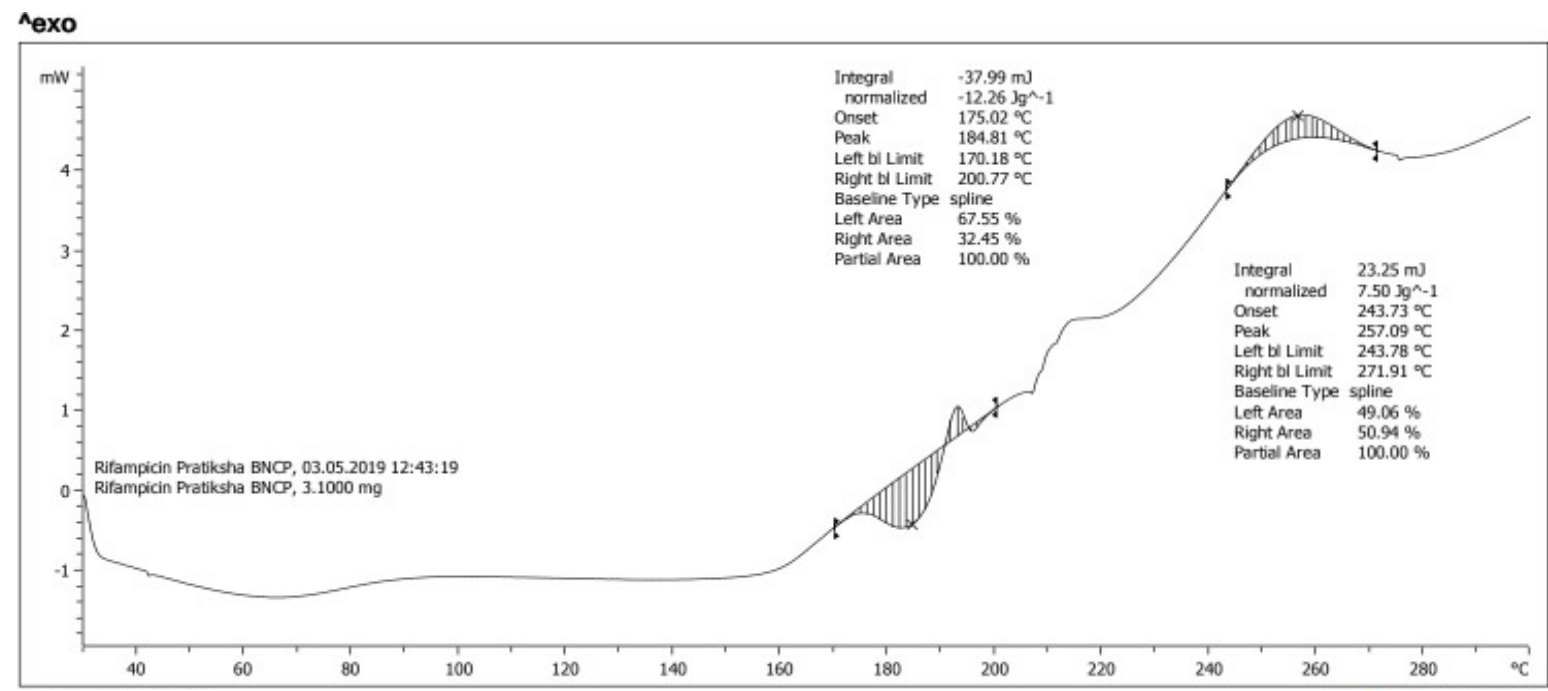

Lab: METTLER

STAR $^{\bullet}$ SW 13.00

Figure 1: DSC endotherm of Rifampicin

Table 1: Interpretation of FTIR spectra of Rifampicin

\begin{tabular}{|l|c|c|}
\hline Functional group & Observed Wave number $\left(\mathrm{cm}^{-1}\right)$ & $\begin{array}{l}\text { Reported Wave } \\
\text { number }\left(\mathrm{cm}^{-1}\right)\end{array}$ \\
\hline $\mathrm{C}=\mathrm{O}$ & 1710.89 & $1725-1700$ \\
\hline Acetyl stretching) & & $3100-3000$ \\
\hline$-\mathrm{C}=\mathrm{N}$ & 2936.67 & $1650-1550$ \\
\hline (asymmetric & 1649.17 & \\
\hline
\end{tabular}




\begin{tabular}{|l|c|l|}
\hline stretching) & & \\
\hline N-H & 1567.35 & $1640-1500$ \\
(Amide bending) & & \\
\hline $\mathrm{C}=\mathrm{C}$ & 1427.35 & $1600-1450$ \\
(stretching) & 1375.27 & $1360-1080$ \\
\hline $\mathrm{C}-\mathrm{N}$ & & \\
(stretch) & & \\
\hline
\end{tabular}

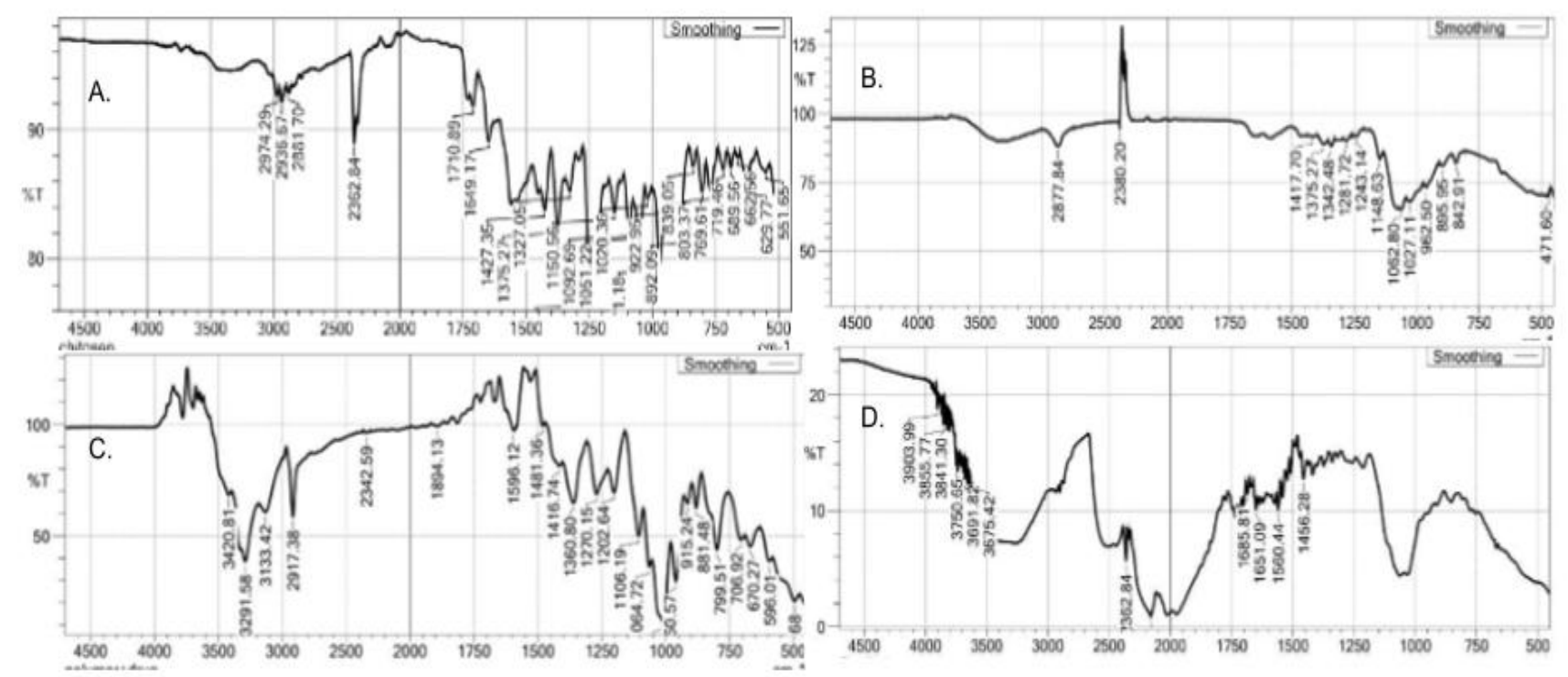

Figure 2: (A.) FTIR Spectra of Rifampicin, (B.) FTIR Spectra of Chitosan, (C.) FTIR Spectra of Mannose and (D.) FTIR Spectra of Chitosan-Mannose conjugate polymer

In the pre-optimization experiments Chitosan nanoparticles were prepared during polymer of different DDA. The objective of performing these experimental trials was to select the suitable grade of Chitosan, for preparing conjugated polymer. Polymeric nanoparticles were prepared using Chitosan $75 \%$ and Chitosan $85 \%$ respectively along with TPP $1 \%$ as crosslinker (Table 2). Nanoparticles 
prepared using $75 \%$ and $85 \%$ DDA were subjected to microscopic observation using Motic. Chitosan with $75 \%$ DDA yielded thread like aggregates and instant gelation of particles was observed. Nanoparticles obtained from Chitosan with $85 \%$ DDA were found to be spherical (Figure 3)

Table 2: Selection of Degree of Deacetylation (DDA) grade of Chitosan

\begin{tabular}{|c|c|c|}
\hline DDA of Chitosan & $75 \%$ & $85 \%$ \\
\hline Concentration of Chitosan (\%) & 1 & 1 \\
\hline Concentration of TPP (\%) & 1 & 1 \\
\hline
\end{tabular}

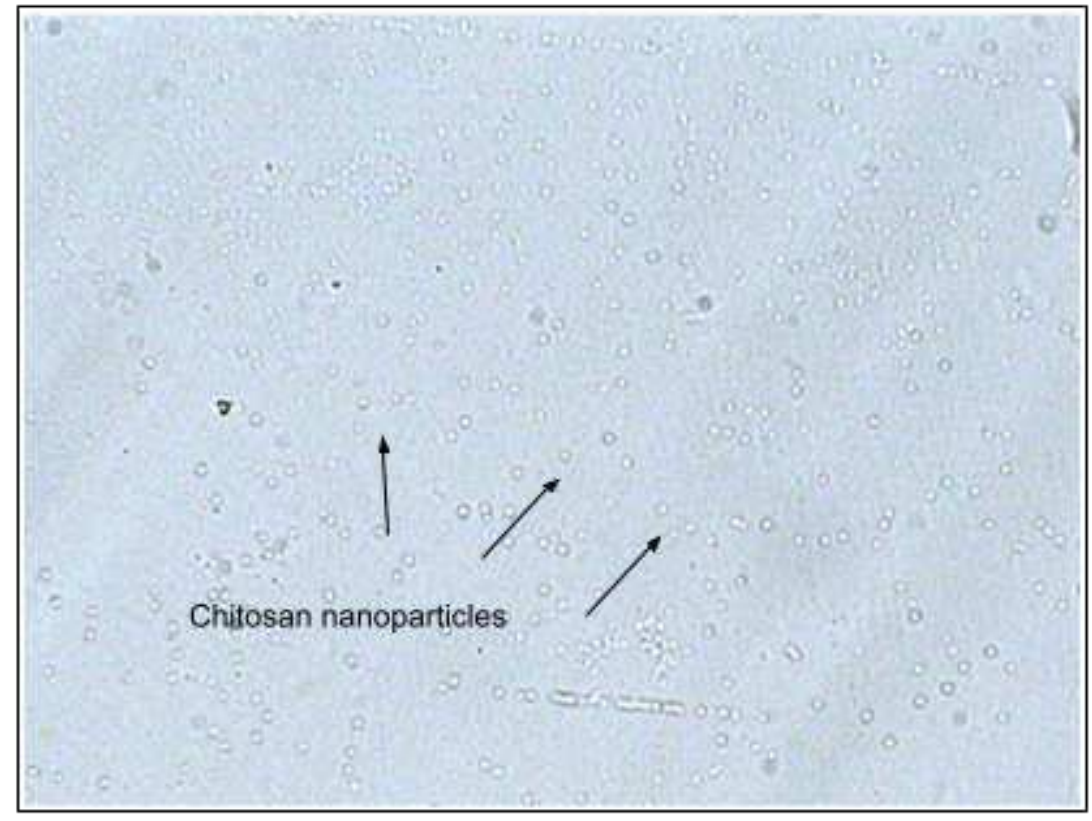

Figure 3: Spherical particles with Chitosan 85\% DDA

The optimum proportion of Chitosan and mannose was obtained by assessing the quality of conjugated polymer prepared using varying concentrations of Chitosan and mannose and STAB as 
reducing agent (Table 3). Mannose conjugated Chitosan polymer prepared by spray drying when freshly prepared was found to be off white and free flowing powder. However as the time elapsed, a drastic change in colour from off white to brown was observed for conjugated polymer. The time required for this colour change was found to be dependent on mannose and STAB proportion. Batch CM5 with reduced concentration of STAB and Chitosan and mannose in the ratio 3:1 gave stable free flowing powder. The conjugation of mannose with Chitosan was ascertained by overlaying the FTIR spectra of Chitosan and mannose with that of conjugated polymer (Table 4 and Figure $2 \mathrm{C}$ ). In the FTIR spectra of Chitosan - mannose conjugate, 2 peculiar peaks were observed at $1560.44 \mathrm{~cm}^{-1}$ and $1456.28 \mathrm{~cm}^{-1}$ indicating $\mathrm{N}-\mathrm{H}$ bending of secondary amine and $\mathrm{C}=\mathrm{N}$ stretch respectively. The formation of Schiff's base ( $\mathrm{R}-\mathrm{CH}=\mathrm{N}-\mathrm{R}$ bond) by ring opening reaction of mannose followed by reaction of the aldehyde group with amino group of chitosan as proved by the above mentioned peaks, confirmed the formation of Mannose conjugated Chitosan (Figure 2D)

Table 3: Optimization of mannose conjugated chitosan polymer

\begin{tabular}{|c|c|c|c|}
\hline Batch No. & Chitosan(g) & D-Mannose(g) & STAB(g) \\
\hline CM1 & 0.6 & 0.2 & 0.2 \\
\hline CM2 & 0.8 & 0.3 & 0.3 \\
\hline CM3 & 0.8 & 0.2 & 0.2 \\
\hline CM4 & 2 & 1 & 0.5 \\
\hline CM5 & 3 & 1 & 0.15 \\
\hline
\end{tabular}


Table 4a: FTIR of Mannose

\begin{tabular}{|l|l|l|}
\hline Functional Groups & Observed Wavenumber $\left(\mathbf{c m}^{-1}\right)$ & Reported wavenumber $\left(\mathbf{c m}^{-1}\right)$ \\
\hline Asymmetric vibration of & 2917.38 & 2920 \\
\hline Bending vibration of CH & 1360.80 & $1480-1350$ \\
\hline Vibration of CO & 1065 & $1150-1050$ \\
\hline
\end{tabular}

Table 4b: FTIR of Chitosan

\begin{tabular}{|c|c|c|}
\hline Functional Groups & Observed Wavenumber $\left(\mathbf{c m}^{-1}\right)$ & Reported wavenumber $\left(\mathbf{c m}^{-1}\right)$ \\
\hline $\begin{array}{c}\text { C-H stretching } \\
\text { symmetric and } \\
\text { asymmetric) }\end{array}$ & 2877.84 & $2921-2877$ \\
\hline $\mathrm{CH}_{2}$ bending & 1375.2 & $1423-1375$ \\
\hline $\mathrm{C}-\mathrm{O}$ stretching & 1027.11 & $1066-1028$ \\
\hline
\end{tabular}

Table 4c: FTIR of Chitosan- Mannose conjugate

\begin{tabular}{|c|c|c|}
\hline Functional Groups & Observed Wavenumber $\left(\mathbf{c m}^{-\mathbf{1}}\right)$ & Reported wavenumber $\left(\mathbf{c m}^{-\mathbf{1}}\right)$ \\
\hline N-H bending of & 1560.44 & 1558.54 \\
\hline Secondary amine & 1456.28 & 1410.1 \\
\hline $\mathrm{C}=\mathrm{N}$ stretch & & \\
\hline
\end{tabular}


In further experimental study, polymeric nanoparticles were prepared using varying concentrations of mannose conjugated Chitosan, TPP and Tween 80 . The speed was maintained in the range of 40006000RPM (Table 5). Drug Entrapment Efficiency of nanoparticles batches M1 and M2 prepared using Chitosan $0.5 \%$ and TPP $0.25 \%$ with Ethanol as solvent was found to be less than $40 \%$. Batches M3M5 batches prepared without Tween 80 were found to be unstable and formed turbid dispersion on storage. Batch M8 with Chitosan 1\%, TPP $0.75 \%$ and Tween $80 \%$ 1\% yielded stable nano dispersion and drug entrapment efficiency of about $70.86 \%$. Batch M8 was subjected to further detailed characterization.

Table 5: Optimization batches, observation of percent entrapment efficiency (\% EE) of rifampicin loaded D-mannose conjugated chitosan nanoparticles (MCNPs)/ rifampicin loaded chitosan nanoparticles (CNPs)

\begin{tabular}{|c|c|c|c|c|c|c|c|c|c|}
\hline $\begin{array}{l}\text { Batch } \\
\text { No. }\end{array}$ & $\begin{array}{l}\text { Chitosan } \\
(\%)\end{array}$ & $\begin{array}{l}\text { TPP } \\
(\%)\end{array}$ & $\begin{array}{l}\text { Drug } \\
(\mathrm{mg})\end{array}$ & $\begin{array}{l}\text { Tween } \\
80 \\
(\%)\end{array}$ & Solvent & $\begin{array}{l}\text { Speed } \\
\text { (RPM) }\end{array}$ & $\begin{array}{l}\% \mathrm{EE} \\
\text { (MCNPs) }\end{array}$ & $\begin{array}{l}\% \mathrm{EE} \\
(\mathrm{CNP} \\
\text { s) }\end{array}$ & Observations \\
\hline M1 & 0.5 & 0.25 & 50 & - & Ethanol & 4000 & 32.99 & - & \multirow{2}{*}{$\begin{array}{l}\text { Few particles } \\
\text { observed under } \\
\text { motic }\end{array}$} \\
\hline M2 & 0.5 & 0.25 & 50 & 0.4 & Ethanol & 4500 & 39.94 & - & \\
\hline M3 & 0.5 & 0.25 & 100 & - & DMSO & 4500 & 39.67 & - & \multirow{3}{*}{$\begin{array}{l}\text { Turbid } \\
\text { dispersion } \\
\text { formed after } 2 \\
\text { days }\end{array}$} \\
\hline M4 & 0.5 & 0.75 & 100 & - & DMSO & 4500 & 42.63 & - & \\
\hline M5 & 1 & 0.25 & 100 & - & DMSO & 4500 & 40.25 & - & \\
\hline
\end{tabular}




\begin{tabular}{|c|c|c|c|c|c|c|c|c|c|}
\hline M6 & 1 & 0.5 & 100 & 0.4 & DMSO & 4500 & 52 & 52.69 & \\
\hline M7 & 1 & 0.5 & 150 & 1 & DMSO & 4500 & 65.64 & 66.23 & nanodispersion \\
\hline M8 & 1 & 0.75 & 150 & 1 & DMSO & 6000 & 70.86 & 73.86 & \\
\hline
\end{tabular}

\subsection{Evaluation of Rifampicin loaded mannose conjugated chitosan nanoparticles}

Rifampicin loaded mannose-conjugated chitosan nanoparticles of Batch M8 were assessed for physicochemical characteristics. For comparative evaluation, nanoparticles were prepared using plain chitosan. In order to determine entrapment efficiency, $10 \mathrm{ml}$ of the dispersion was centrifuged at 15 , $000 \mathrm{RPM}$ at $4^{\circ} \mathrm{C}$ for 20 minutes. The supernatant was collected, diluted with methanol and analyzed for free drug. Entrapment Efficiency was determined by using the following formula: (26)

$\%$ Entrapment Efficiency $=\frac{\text { Total Drug }- \text { Free Drug } * 100}{\text { Total Drug }}$

$\%$ Entrapment efficiency of mannose conjugated chitosan nanoparticles and chitosan nanoparticles was found to be 70.86 and 73.86 respectively indicating appreciable drug loading capacity of formulation and conjugation of mannose with chitosan did not have significant effect on entrapment efficiency.

Particle size determined by dynamic light scattering indicated size of $138 \mathrm{~nm}$ with PDI of 0.173 for plain Chitosan nanoparticles whereas for mannose conjugated Chitosan nanoparticles, the size was observed to be $142 \mathrm{~nm}$ with PDI of 0.154 (Figure 4A and 4B). It was concluded that the coupling of mannose in chitosan caused slight increase in the size of nanoparticles prepared using conjugated polymer. Zeta potential of Chitosan particles was found to be $42.6 \mathrm{mV}$ whereas zeta potential of mannose conjugated Chitosan particles was found to be $38.5 \mathrm{mV}$. The reduction in 
zeta potential was attributed to conjugation of mannose to Chitosan resulting in reduction of primary amino groups as they couple to CHO groups of Mannose (Figure 4C)(27).

Surface morphology of mannose-conjugated chitosan nanoparticles and chitosan nanoparticles was compared by performing Scanning Electron Microscopy (SEM) (Figure 5). The formulations were placed on circular aluminum stubs using double adhesive tape, coated with Gold in HUS-5 GB vacuum evaporator, and observed in SEM at an acceleration voltage of $10 \mathrm{kV}$ and a magnification of $5000 \mathrm{X}$ (28). SEM images revealed that plain chitosan nanoparticles were spherical whereas mannose conjugated chitosan nanoparticles were found to be platelet shaped with pitted surface. This peculiar characteristic was attributed because of conjugation of mannose with chitosan and we are postulating that this peculiar shape will enhance the uptake of nanoparticles by macrophages.

Dialysis sac method was used to determine their lease of drug from nanoparticulate formulation. Drug release studies from mannose conjugated chitosan nanoparticles were performed in simulated synovial fluid $\mathrm{pH} 7.4$ and simulated endosomal fluid $\mathrm{pH}$ 5.2(Table 6 and Figure 6).The drug release was found to be about $70.7 \%$ at the end of 12 hours in simulated synovial fluid whereas the drug release in simulated endosomal fluid was $89.17 \%$. Higher percent drug release in simulated endosomal fluid was indicative of preferential uptake of nanoparticles by macrophages and drug release in its endosomal contents.

In order to understand the kinetics and mechanism of drug release, the results of in vitro drug dissolution studies of optimized formulation were fitted in various kinetics models like zero order (percent cumulative drug release vs. time), first order (log percent drug remaining vs. time), Higuchi's model (percent cumulative drug release vs. square root of time), Korsmeyer-Peppas plot (log of percent cumulative drug released vs. log of time) (Table 7). The higher value of regression for 
percent cumulative drug release vs. time indicated that drug release from conjugated chitosan nanoparticles followed zero order kinetics

\subsection{Development and evaluation of In situ gelling system containing Mannose conjugated Chitosan nanoparticles}

Various gelling agents such as Chitosan 75\% DDA (1-2\%), Deacetylated Gellan Gum, Sodium Alginate (1-2\%), Poloxamer $407(10-15 \%)$ in combination with HPMC K4M (0.5\%)were used to formulate in situ gelling system . The composition and proportion of the polymers were optimized based on clarity, syringeability, gelation time, gelling capacity. Gellan gum being anionic polymer showed incompatibility with cationic chitosan nanoparticles, hence it was not considered for further optimization. Poloxamer $407(15 \%)$ in combination with HPMC formed a stable in situ gel at $37^{\circ} \mathrm{C}$ when subjected to simulated synovial fluid $(23,29,30)$ (Table 8). Rifampicin loaded mannose conjugated chitosan nanoparticles were incorporated in in situ gelling system and evaluated for drug release in simulated synovial fluid for period of 40 hours. Incorporation of nanoparticles in gelling system prolonged the drug release considerably. Cumulative percent release at the end of 40 hours was about $70.3 \%$ (Table 9 and Figure 7).

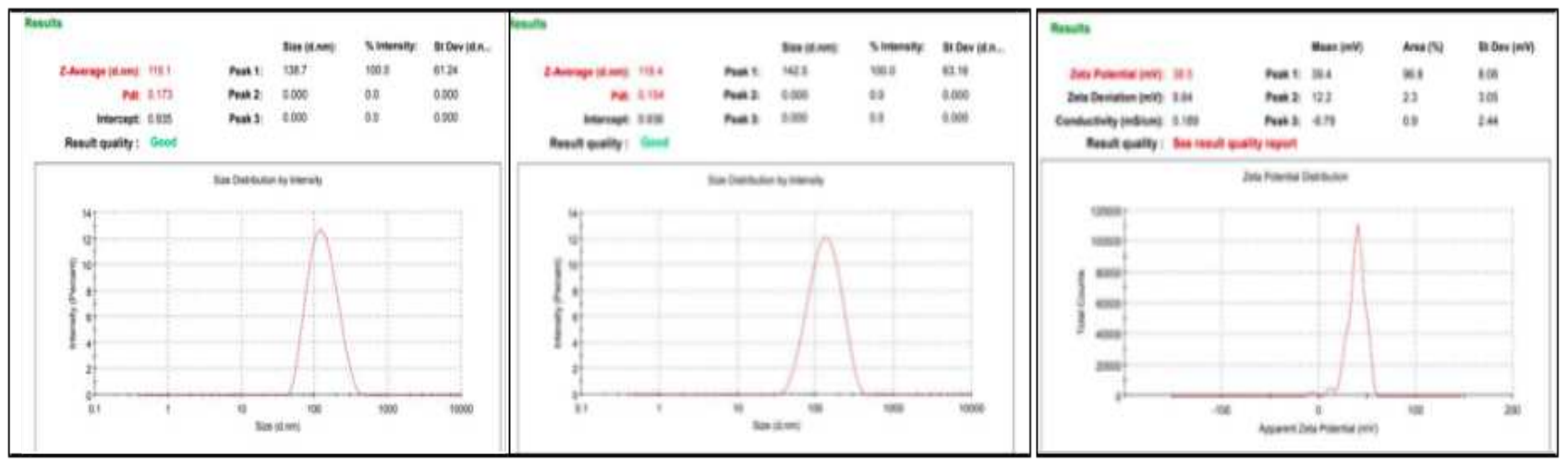


Figure 4 : (A.) Particle size of Chitosan nanoparticles, (B.) Particle size of mannose conjugated Chitosan nanoparticles and (C.) Zeta potential of mannose conjugated Chitosan nanoparticles

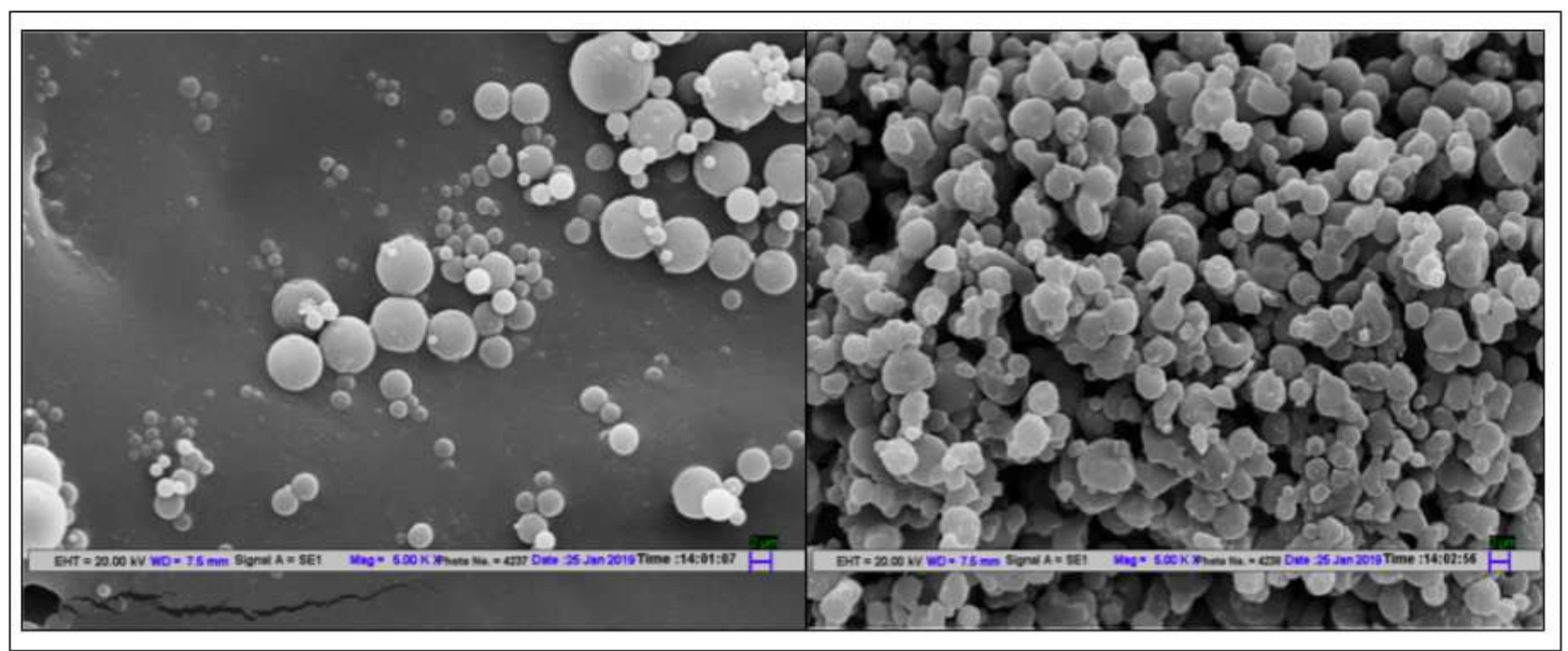

Figure 5: (A.) SEM image of Chitosan nanoparticles and (B.) SEM image of mannose conjugated Chitosan nanoparticles

Table 6: Drug release studies of mannose conjugated Chitosan nanoparticles

\begin{tabular}{|c|c|c|}
\hline Time & $\begin{array}{c}\text { Percent cumulative drug release } \\
\text { in simulated synovial fluid } \\
\mathrm{pH} 7.4(\mathrm{n}=3)\end{array}$ & $\begin{array}{c}\text { Percent cumulative drug release in } \\
\text { simulated endosomal fluid } \mathrm{pH} 5.2 \\
(\mathrm{n}=3)\end{array}$ \\
\hline 30 minutes & 3.237 & 4.639 \\
\hline 1 hour & 4.333 & 5.765 \\
\hline 2 hours & 6.846 & 23.652 \\
\hline 3 hours & 13.907 & 40.8155 \\
\hline 4 hours & 20.971 & 43.055 \\
\hline
\end{tabular}




\begin{tabular}{|c|c|c|}
\hline 5 hours & 30.603 & 57.475 \\
\hline 6 hours & 38.303 & 58.486 \\
\hline 7 hours & 47.09 & 67.01 \\
\hline 8 hours & 54.104 & 80.319 \\
\hline 9 hours & 64.075 & 82.798 \\
\hline 10 hours & 66.124 & 85.207 \\
\hline 11 hours & 69.496 & 87.318 \\
\hline 12 hours & 70.75 & 89.172 \\
\hline
\end{tabular}

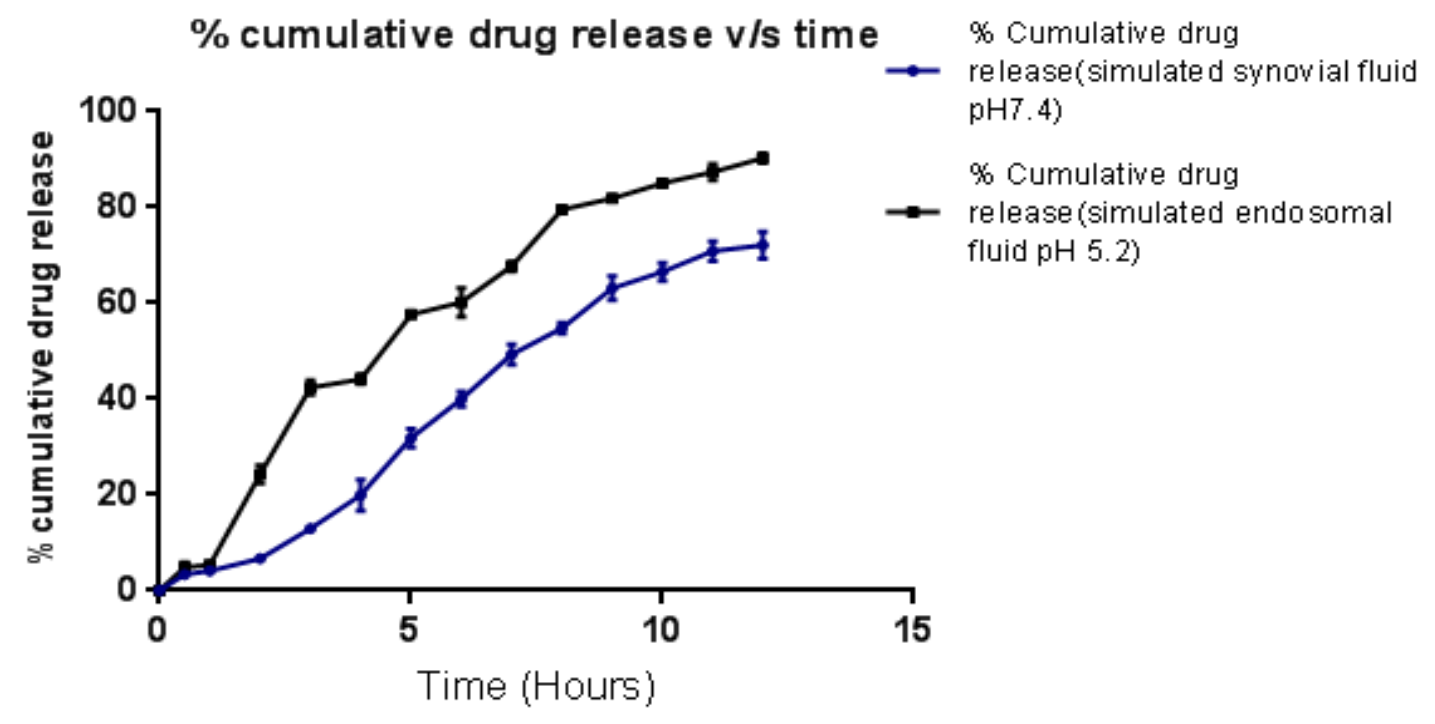

Figure 6: Graph depicting percent cumulative drug release versus time for mannose conjugated Chitosan nanoparticles in simulated synovial fluid and simulated endosomal fluid 
Table 7: Drug Release Kinetics for mannose conjugated Chitosan nanoparticles in simulated synovial fluid

\begin{tabular}{|c|l|l|l|l|}
\hline Model & Zero order & First order & Korsmeyer-Peppas & Higuchi \\
\hline $\begin{array}{l}\text { Regression } \\
\text { coefficient }\end{array}$ & 0.971 & 0.903 & 0.745 & 0.812 \\
\hline
\end{tabular}

Table 8 : Evaluation of various polymers for the formation of in-situ gel

\begin{tabular}{|l|l|l|l|l|}
\hline Polymers & Gelling ability & Syringeability & Clarity & Inference \\
\hline Gellan gum & Good & Good & Good & $\begin{array}{l}\text { Incompatible with the polymeric } \\
\text { nanoparticles }\end{array}$ \\
\hline Chitosan & Poor & Good & Good & Gelling ability was not optimum \\
\hline Sodium & Poor & Good & Good & Gelling ability was not optimum \\
\hline Poloxamer & Good & Good & Good & $\begin{array}{l}\text { Optimum gelling with good } \\
\text { gelling ability of more than 12 } \\
\text { hours and good syringeability }\end{array}$ \\
\hline
\end{tabular}


Table 9: Drug release studies from mannose conjugated Chitosan nanoparticles incorporated in in situ gelling system.

\begin{tabular}{|c|c|}
\hline Time (hours) & $\begin{array}{l}\text { Percent Cumulative drug release } \\
\text { in simulated synovial fluid }(\mathrm{n}=3)\end{array}$ \\
\hline 0.5 & 2.036 \\
\hline 1 & 2.364 \\
\hline 2 & 3.325 \\
\hline 3 & 8.325 \\
\hline 4 & 12.907 \\
\hline 5 & 20.355 \\
\hline 6 & 28.306 \\
\hline 7 & 31.752 \\
\hline 8 & 37.276 \\
\hline 9 & 41.985 \\
\hline 10 & 43.587 \\
\hline 24 & 45.367 \\
\hline 28 & 50.321 \\
\hline 32 & 58.346 \\
\hline 36 & 65.321 \\
\hline
\end{tabular}


$\%$ cumulative drug release $\mathrm{v} / \mathrm{s}$ time (In-situ gel)

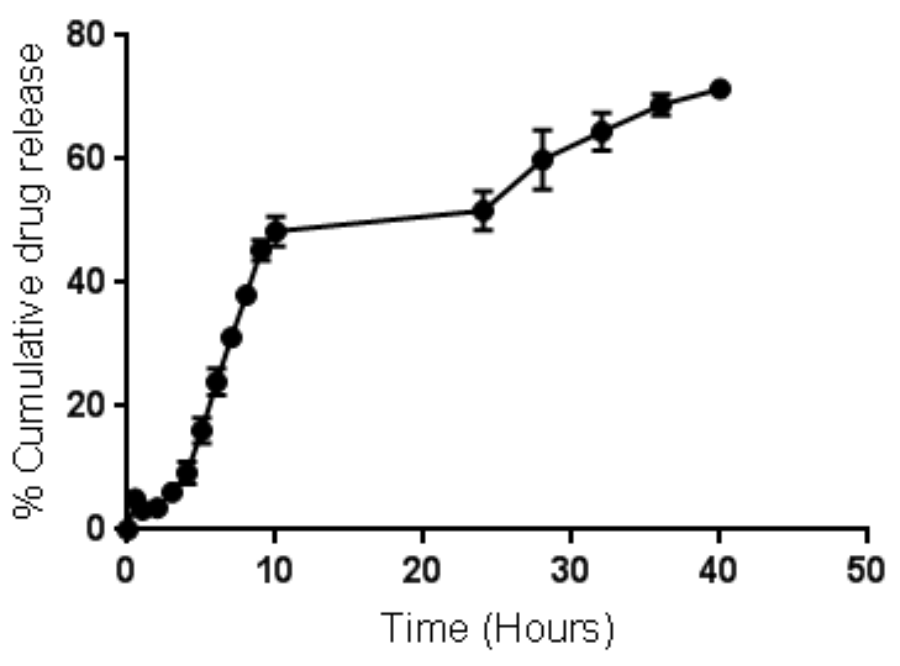

Figure 7 Graph depicting percent cumulative drug release versus time for in-situ gel loaded with mannose conjugated Chitosan nanoparticles in simulated synovial fluid

The drug release kinetics was computed and it was observed to be following zero order kinetics (Table 10)

Table 10: Drug release kinetics of Rifampicin loaded mannosylated chitosan nanoparticles in in situ gel

\begin{tabular}{|l|l|l|l|l|}
\hline Model & Zero order & First order & Korsmeyer Peppas & Higuchi \\
\hline $\begin{array}{l}\text { Regression } \\
\text { coefficient }\end{array}$ & 0.836 & 0.806 & 0.732 & 0.709 \\
\hline
\end{tabular}




\section{Conclusion}

A promising targeted delivery system consisting of ligand conjugated Rifampicin nanoparticles incorporated in in situ gel was developed to tackle the drawbacks associated with the conventional treatment of osteoarticular tuberculosis. Rifampicin loaded mannose conjugated chitosan nanoparticles were prepared by ionic gelation technique. Mannose conjugated Chitosan nanoparticles showed preferential drug release in endosomal fluid indicative of preferential uptake of nanoparticles by macrophages and drug release in its endosomal contents. In vitro drug release of mannose conjugated Rifampicin nanoparticles incorporated in in situ gel system showed prolonged release for 40 hours. Based on the initial encouraging results obtained, the nanoparticles are being envisaged for ex-vivo cellular uptake study using TB infected macrophages.

\section{ETHICAL STATEMENT:}

- Ethics approval and consent to participate: NA

- Consent for publication: NA

- Availability of data and materials: The datasets generated during and/or analysed during the current study are available from the corresponding author on reasonable request.

- Competing interests: The authors have no conflicts of interest/ competing interest to declare that are relevant to the content of this article.

- Funding: The authors did not receive support from any organization for the submitted work.

- Authors' contributions: All authors contributed to the study and manuscript conception and design.

- $\quad$ Material preparation, data collection and analysis were performed by Ms Pratiksha Prabhu.

- The research activity planning, execution and supervision was carried out under the guidance of Dr Sujata Sawarkar and Dr Pramila Chaubey. The first draft of the manuscript was written by Dr Sujata Sawarkar. Revisions and editing was done by Ms Trinette Fernandes.

- $\quad$ All authors commented on previous versions of the manuscript, read and approved the final manuscript.

- Acknowledgements: The authors wish to thank Sophisticated Analytical Instrument Facility, IIT-Bombay, Powai for their providing SEM analysis samples which are used in this manuscript. 
- Authors' information (optional):

- Pratiksha Prabhu

Research Student,

Department of Pharmaceutics

SVKM's Dr. Bhanuben Nanavati College of Pharmacy,

Mithibai college Campus, Gate no. 1,

V. M. Road, Vile Parle (W),

Mumbai - 400056

Email : pratu2395@gmail.com

- Trinette Fernandes:

Research Student

Department of Pharmaceutics

SVKM's Dr. Bhanuben Nanavati College of Pharmacy

SVKM campus, Gate no. 1,

V. M. Road, Vile Parle (W),

Mumbai - 400056

Ph No.: +919960824024

Email: trinette.fernz@gmail.com

ORCID:https://orcid.org/0000-0003-3831-4366

- Pramila Chaubey

Department of Pharmaceutics,

College of Pharmacy, Shaqra University,

Al-Dawadmi, Saudi Arabia

Email: cpramil@gmail.com

ORCID:https://orcid.org/0000-0003-2889-9452

\section{Corresponding Author:}

- Dr. Sujata P. Sawarkar

Professor in Pharmaceutics,

Department of Pharmaceutics,

SVKM's Dr. Bhanuben Nanavati College of Pharmacy,

Vile Parle, Mumbai, India.

Tel. 022-42332052

E-mail: sujata.sawarkar@bncp.ac.in, sujatasawarkar19@gmail.com

ORCiD: https://orcid.org/0000-0003-0473-4979 


\section{References}

1. Bhowmik CD, Chandira RM, Jayakar B, Kumar KPS. Recent Trends of Drug Used Treatment of Tuberculosis. J Chem Pharm Res. 2009;1(1):113-33.

2. Davidson PT, Horowitz I. Skeletal tuberculosis. A review with patient presentations and discussion. Am J Med. 1970;48(1):77-84.

3. Sequeira, W. and Block J. Osteoarticular tuberculosis: current diagnosis and treatment American journal of therapeutics. 2000 Nov 1;7(6):393-8.

4. Procopie I, Popescu EL, Huplea V, Pleșea RM, Ghelase Ș M, Stoica GA, et al. Osteoraticular Tuberculosis-Brief Review of Clinical Morphological and Therapeutic Profiles. Curr Heal Sci J. 2017;43(3):171-90.

5. Tuli SM, Brighton CT, Morton HE, Clark LW. The experimental induction of localised skeletal tuberculous lesions and their accessibility to streptomycin. J Bone Jt Surg - Ser B. 1974;56(3):551-9.

6. Pandita A, Madhuripan N, Pandita S, Hurtado RM. Challenges and controversies in the treatment of spinal tuberculosis. Journal of clinical tuberculosis and other mycobacterial diseases. 2020 May 1;19:100151.

7. Diseases C. WHO REPORT 2003 WHO REPORT 2003 Global Tuberculosis Control. 2003;

8. 7. Sawarkar, S.P., 2017. Targeting approaches for effective therapeutics of bone tuberculosis abstract symptoms of bone tuberculosis. Journal of Pharmaceutical Microbiology. 2017;3(1):1-3.

9. Chan ED, Iseman MD. Clinical review Current medical treatment for tuberculosis. $\mathrm{Br}$ Med J. 2002;325(7375):1282-6. 
10. Organization WH. ANTI-TUBERCULOSIS DRUG RESISTANCE IN THE WORLD Third Global Report The WHO/IUATLD Global Project on Anti-tuberculosis Drug Resistance Surveillance . 1999

11. Sosnik A, Glisoni R, Moretton MA, Carcaboso ÁM, Glisoni RJ, Chiappetta DA. New old challenges in tuberculosis: Potentially effective nanotechnologies in drug delivery Production of pure drug nanoparticles. Adv Drug Deliv Rev ;62:547-59.

12. Lee J, Hartman M, Kornfeld H. Macrophage apoptosis in tuberculosis. Yonsei Med J. 2009;50(1):1-11.

13. Ramón-García S, Mikut R, Ng C, Ruden S, Volkmer R, Reischl M, et al. Targeting Mycobacterium tuberculosis and Other Microbial Pathogens Using Improved Synthetic Antibacterial Peptides. Am Soc Microbiol . 2013; Available from: http://dx.doi.org/10.1128

14. Stahl PD. The mannose receptor and other macrophage lectins. Curr Biol. 1992;2(4):183.

15. Chaubey P, Mishra B. Mannose-conjugated chitosan nanoparticles loaded with rifampicin for the treatment of visceral leishmaniasis. Carbohydr Polym. 2014;101(1):1101-8.

16. Chaubey P, Patel RR, Mishra B. Development and optimization of curcumin-loaded mannosylated chitosan nanoparticles using response surface methodology in the treatment of visceral leishmaniasis. Expert Opin Drug Deliv. 2014;11(8):1163-81.

17. Abdelgawad AM, Hudson SM. Chitosan nanoparticles: Polyphosphates cross-linking and protein delivery properties. Int J Biol Macromol. 2019;136:133-42.

18. Goñi MG, Tomadoni B, Roura SI, Moreira M del R. Lactic acid as potential substitute of acetic acid for dissolution of chitosan: preharvest application to Butterhead lettuce. J Food Sci Technol. 2017;54(3):620-6. 
19. Vandervoort J, Ludwig A. Preparation and evaluation of drug-loaded gelatin nanoparticles for topical ophthalmic use. Eur J Pharm Biopharm. 2004;57(2):251-61.

20. Marques MRC, Loebenberg R, Almukainzi M. Simulated biological fluids with possible application in dissolution testing. Dissolution Technol. 2011;18(3):15-28.

21. Rabel M, Warncke P, Grüttner C, Bergemann C, Kurland HD, Müller R, et al. Simulation of the long-term fate of superparamagnetic iron oxide-based nanoparticles using simulated biological fluids. Nanomedicine. 2019;14(13):1681-706.

22. Thing M, Mertz N, Ågårdh L, Larsen SW, Østergaard J LC. Simulated synovial fluids for in vitro drug and prodrug release testing of depot injectables intended for joint injection. $\mathrm{J}$ Drug Deliv Sci Technol. 2019 Feb 1;49:169-76.

23. Talasaz AHH, Ghahremankhani AA, Moghadam SH, Malekshahi MR, Atyabi F, Dinarvand R. In situ gel forming systems of poloxamer 407 and hydroxypropyl cellulose or hydroxypropyl methyl cellulose mixtures for controlled delivery of vancomycin. J Appl Polym Sci. 2008 Aug;109(4):2369-74.

24. Levy G, Amherst NY. OCTOBER 1986 Cl 183. AUC 180. Vol. 106, J. ALLERGY CLIN. IMMUNOL. 1985 [cited 2021 Mar 30].

25. Drapeau CMJ, Grilli E, Petrosillo N. Rifampicin combined regimens for Gram-negative infections: data from the literature. Int J Antimicrob Agents. 2010;35(1):39-44.

26. Kumar PV, Asthana A, Dutta T, Jain NK. Intracellular macrophage uptake of rifampicin loaded mannosylated dendrimers. J Drug Target. 2006 Sep;14(8):546-56.

27. Patel BK, Parikh RH, Aboti PS. Development of Oral Sustained Release Rifampicin Loaded Chitosan Nanoparticles by Design of Experiment. J Drug Deliv. 2013;2013:1-10.

28. Lazaridou M, Christodoulou E, Nerantzaki M, Kostoglou M, Lambropoulou DA, 
Katsarou A, et al. Formulation and in-vitro characterization of chitosan-nanoparticles loaded with the iron chelator deferoxamine mesylate (DFO). Pharmaceutics. 2020;12(3).

29. Mayol L, Quaglia F, Borzacchiello A, Ambrosio L, Rotonda MIL. A novel poloxamers/hyaluronic acid in situ forming hydrogel for drug delivery: Rheological, mucoadhesive and in vitro release properties. Eur J Pharm Biopharm. 2008 Sep;70(1):199-206.

30. Radivojša M, Grabnar I, Grabnar PA. Thermoreversible in situ gelling poloxamer-based systems with chitosan nanocomplexes for prolonged subcutaneous delivery of heparin: Design and in vitro evaluation. Eur J Pharm Sci. 2013;50(1):93-101. 


\section{Figures}

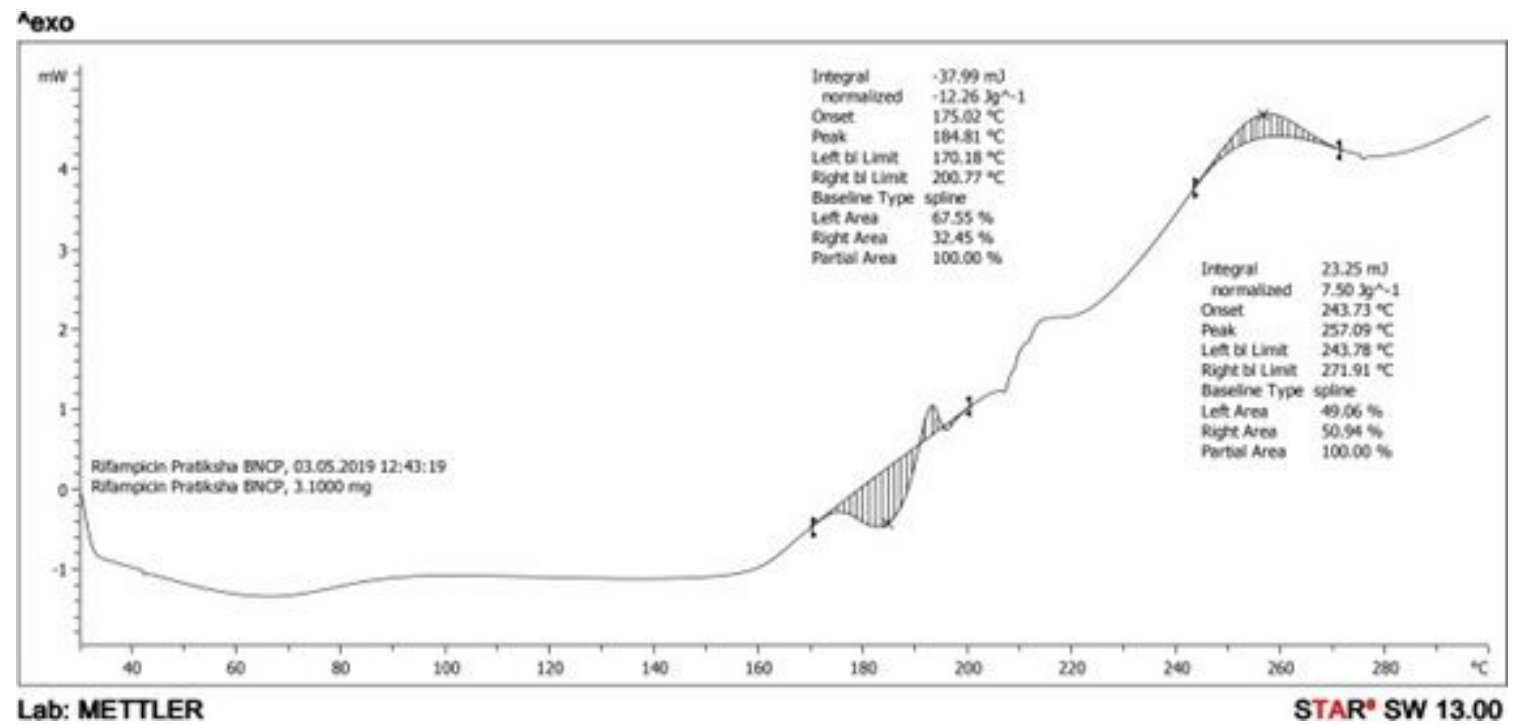

Figure 1

DSC endotherm of Rifampicin

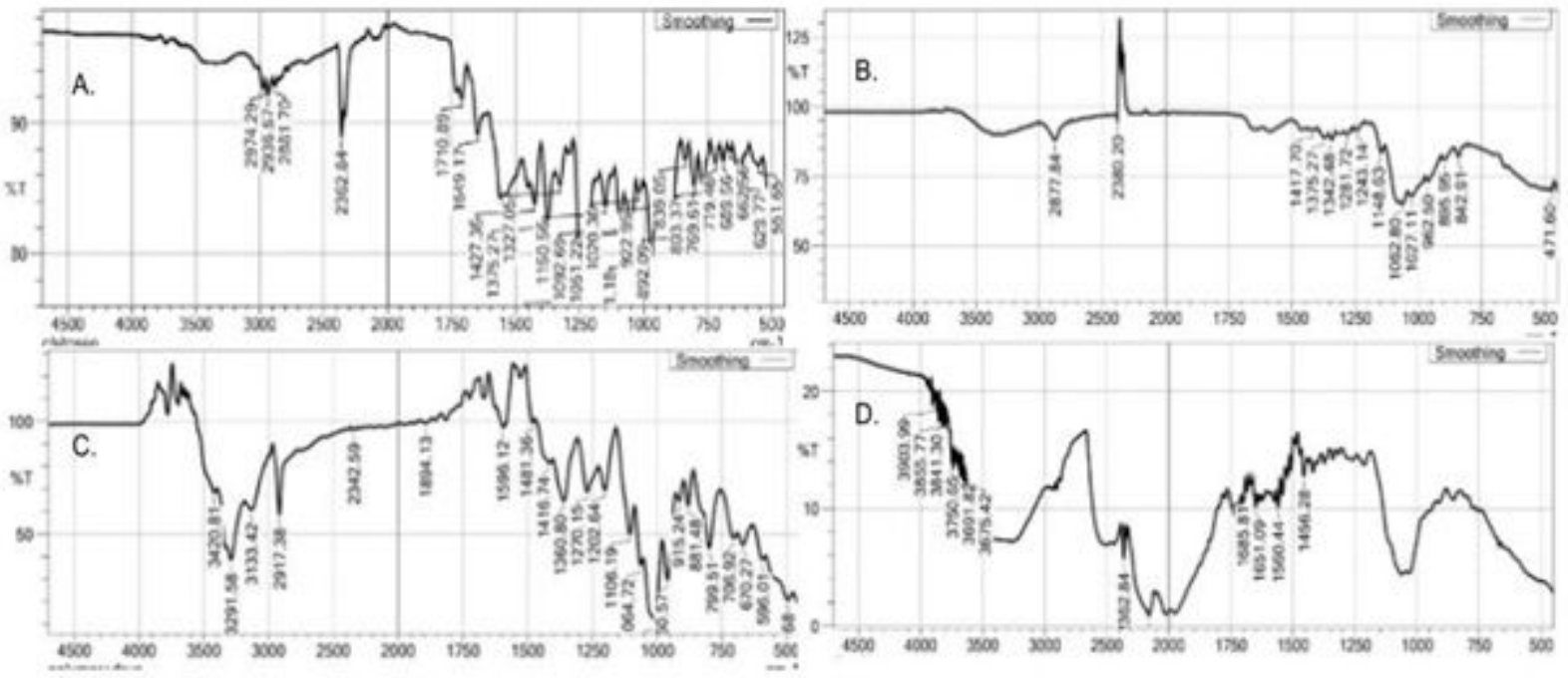

Figure 2

(A.) FTIR Spectra of Rifampicin, (B.) FTIR Spectra of Chitosan, (C.) FTIR Spectra of Mannose and (D.) FTIR Spectra of Chitosan-Mannose conjugate polymer 


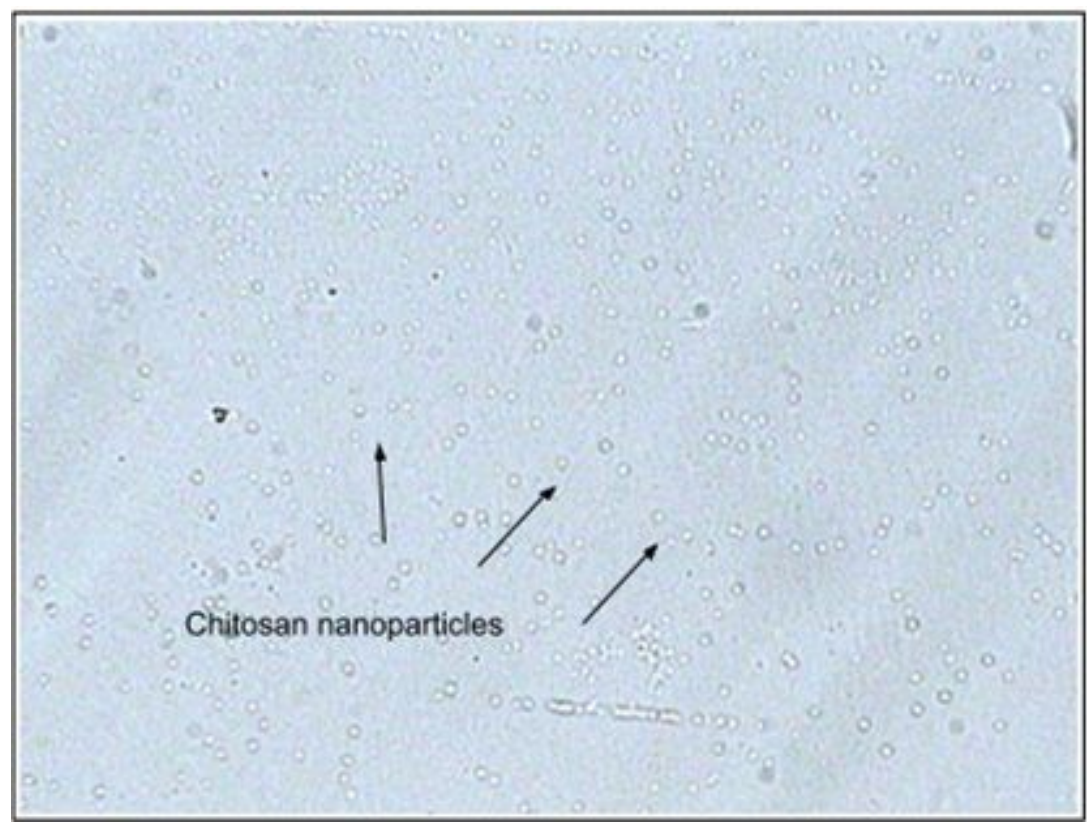

Figure 3

Spherical particles with Chitosan 85\% DDA

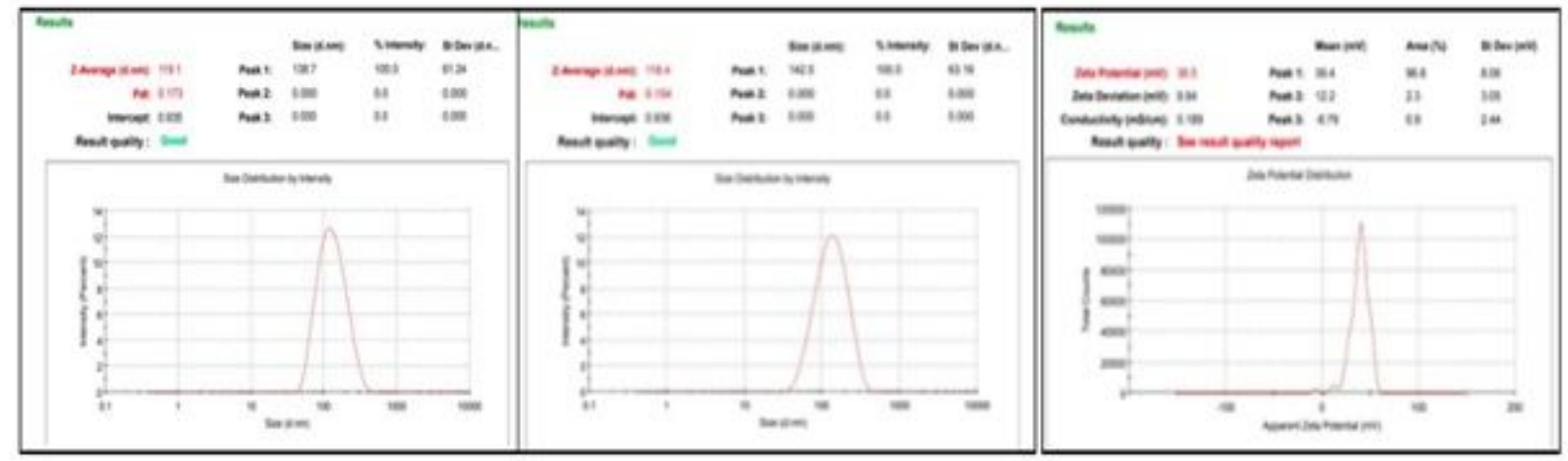

Figure 4

(A.) Particle size of Chitosan nanoparticles, (B.) Particle size of mannose conjugated Chitosan nanoparticles and (C.) Zeta potential of mannose conjugated Chitosan nanoparticles

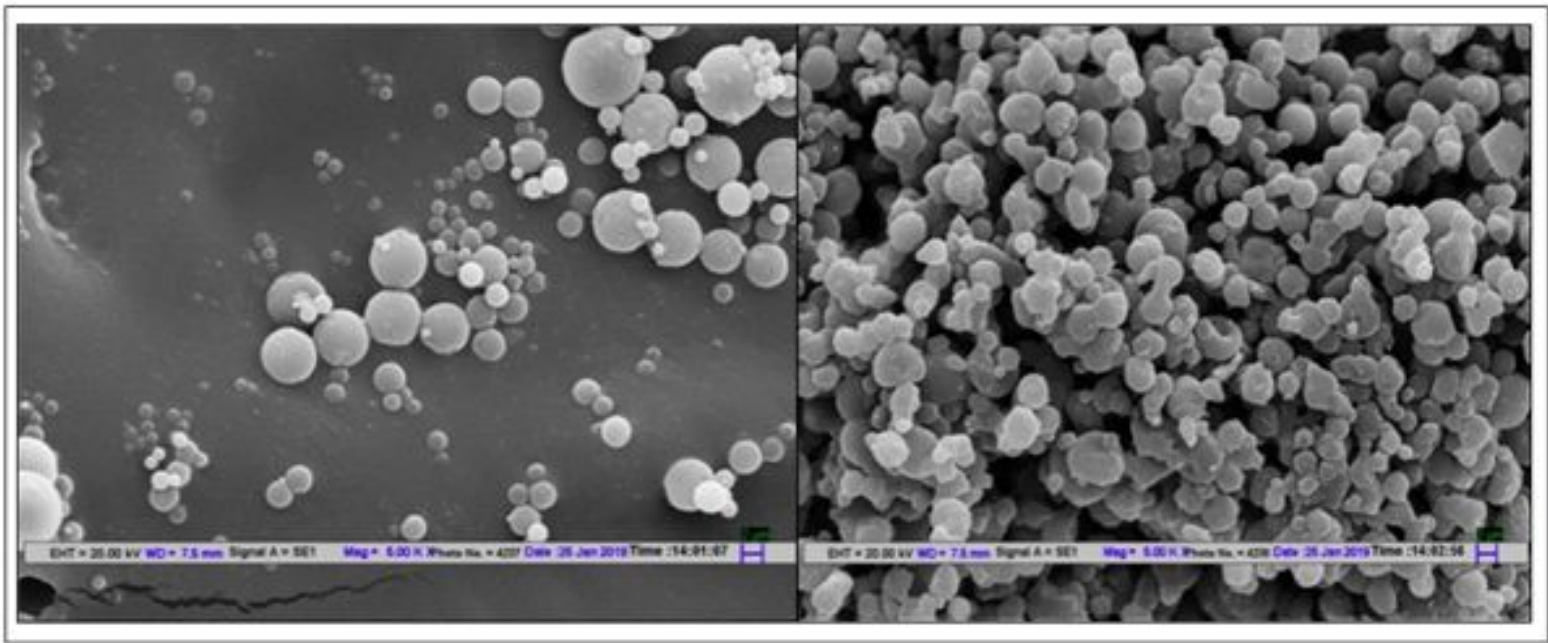


Figure 5

(A.) SEM image of Chitosan nanoparticles and (B.) SEM image of mannose conjugated Chitosan nanoparticles

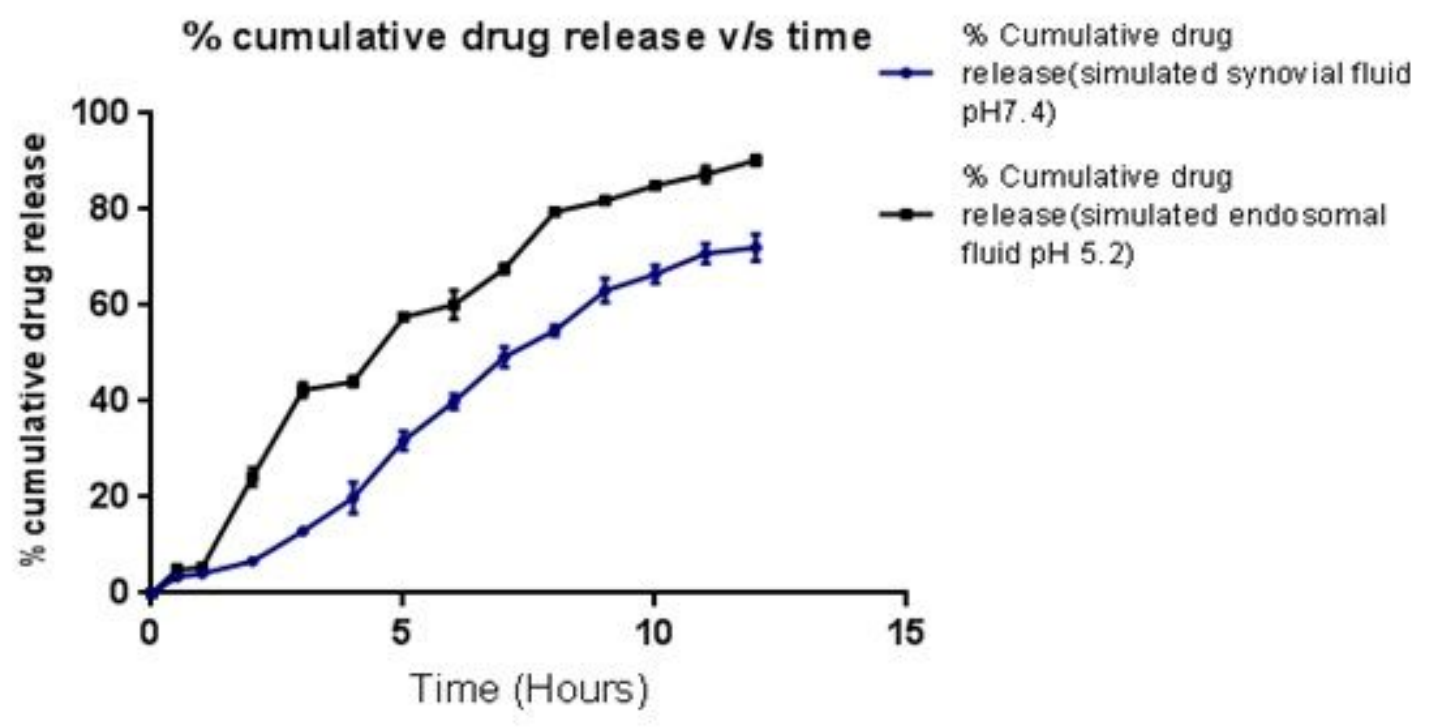

Figure 6

Graph depicting percent cumulative drug release versus time for mannose conjugated Chitosan nanoparticles in simulated synovial fluid and simulated endosomal fluid

\section{$\%$ cumulative drug release $\mathrm{v} / \mathrm{s}$ time (In-situ gel)}

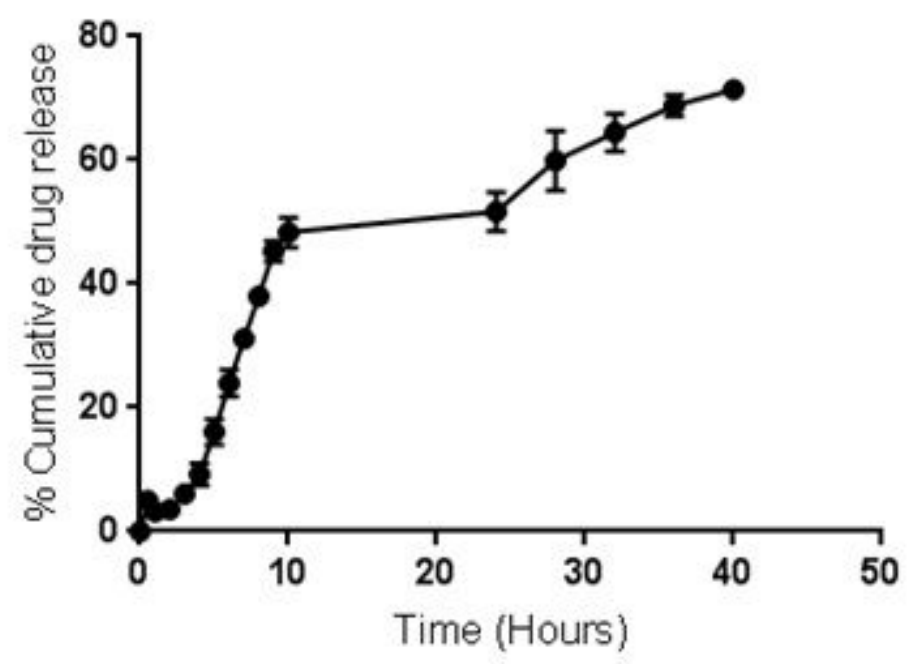

Figure 7 
Graph depicting percent cumulative drug release versus time for in-situ gel loaded with mannose conjugated Chitosan nanoparticles in simulated synovial fluid

\section{Supplementary Files}

This is a list of supplementary files associated with this preprint. Click to download.

- graphicalabstract.jpg 